\title{
COLHEITA E QUALIDADE FISIOLÓGICA DAS SEMENTES DE ARROZ IRRIGADO CULTIVAR BRS JABURU EM RORAIMA
}

\author{
Harvesting and physiologic quality of irrigated rice seeds \\ of cultivar BRS Jaburu in Roraima
}

\section{Oscar José Smiderle ${ }^{1}$, Paulo Roberto Valle da Silva Pereira ${ }^{2}$, Antonio Carlos Centeno Cordeiro ${ }^{3}$}

\footnotetext{
${ }^{1}$ Pesquisador D. Sc. Embrapa Roraima. Roraima, RR - Brsil. e-mail: ojsmider@cpafrr.embrapa.br

${ }^{2}$ Pesquisador D. Sc. Embrapa Trigo. Passo Fundo, RS - Brasil. e-mail: paulo@cnpt.embrapa.br

${ }^{3}$ Pesquisador D. Sc. Embrapa Roraima. Roraima, RR - Brasil. e-mail: ojsmider@cpafrr.embrapa.br
}

\section{Resumo}

A época de colheita é um dos fatores mais importantes que influenciam as características da semente de arroz. Com o objetivo de determinar uma faixa adequada de colheita do arroz (Oryza sativa L.) irrigado BRS Jaburu, sementes dessa cultivar foram colhidas aos 22, 29, 36, 43, 50 e 57 dias após o florescimento e avaliadas quanto à umidade, viabilidade, massa seca de 100 sementes, produtividade e qualidade durante doze meses de armazenamento. As sementes colhidas aos 22 dias após o florescimento apresentaram boa qualidade, mesmo tendo alto valor de umidade inicial. Sementes colhidas aos 57 dias apresentam perda de qualidade no armazenamento. A melhor faixa de colheita, na cultivar BRS Jaburu, é dos 29 a 36 dias após o florescimento, quando as sementes apresentam maior qualidade, produtividade e reduzida dormência.

Palavras-chave: Oryza sativa; Umidade; Produtividade; Armazenamento; Roraima.

\begin{abstract}
Harvesting time is one of most important factors which influence rice seed characteristics. With the objective of determining the proper period to harvest irrigated rice (Oryza sativa L.) BRS Jaburu, seeds of this cultivar were harvested 22, 29, 36, 43, 50 e 57 days after flowering and evaluated in relation to moisture, viability, dry mass of 100 seeds, productivity and quality within twelve months storability. Seeds harvested 22 days after flowering showed good quality, although presenting high content of initial humidity. Seeds harvested at the $57^{\text {th }}$ day showed loss of quality concerning storage. The best harvesting period, for BRS Jaburu, was between 29 an 36 days after flowering, when seeds presented higher quality, yield and reduced dormancy.
\end{abstract}

Keywords: Oryza sativa; Moisture; Productivity; Storage; Roraima. 


\section{INTRODUÇÃO}

A qualidade física e fisiológica da semente de arroz depende da cultivar, estádio de maturação, conteúdo de umidade e danos mecânicos (impactos, abrasões e tensões) que podem ocorrer durante a colheita, secagem, beneficiamento e mesmo no armazenamento.

Colher na época certa é de fundamental importância para obter-se um produto de melhor qualidade. $\mathrm{O}$ arroz atinge o ponto de maturação adequado quando dois terços dos grãos da panícula estão maduros. A colheita antecipada, com umidade elevada, aumenta a proporção de grãos malformados e gessados. $\mathrm{O}$ arroz colhido tardiamente, com umidade muito baixa, afeta a produtividade pela degrana natural (DORFMAN; ROSA, 1980).

Arroz trincado é mais susceptível à infestação por insetos. O trincamento também tem a desvantagem de poder reduzir a viabilidade ou o valor de plantio do arroz para semente. Trincas que ocorrem por meio de toda a secção da semente diminuem o vigor da plântula pela redução da disponibilidade de endosperma e, conseqüentemente, de nutrientes durante a fase de germinação e emergência (STEFFE; SINGH; MILLER JR., 1980).

Colheita precoce resulta em decréscimo na produção pelo desenvolvimento incompleto das sementes, que se apresentam com alto conteúdo de umidade, freqüentemente estão gessadas. Um excessivo número de sementes imaturas também é produzido quando utilizadas cultivares de maturação desuniforme. Grãos gessados, além de conferirem má aparência ao produto acabado, são mais fracos e quebram-se nas operações de beneficiamento (JULIANO, 1980; LUH; MICKUS, 1980; WEBB, 1980).

O estádio de maturação também influencia a viabilidade e o vigor dos grãos de arroz para fins de semeadura. O ponto de completa maturação da semente é geralmente considerado como o ponto em que ela atinge a máxima massa seca durante a fase de desenvolvimento e maturação no campo (RAJANNA; ANDREWS, 1970; GONÇALO; MACIEL, 1975). Em São Paulo, Lago et al. (1991) verificaram que o melhor intervalo de colheita da cultivar IAC 4440 (arroz irrigado) é o de 36 a 43 dias após o florescimento. Sementes colhidas antes da completa maturação são mais leves, mal formadas e menos vigorosas, com reflexos negativos no armazenamento e após o plantio no campo.

A dormência em sementes de arroz, principalmente quando recém-colhidas, pode apresentar obstáculos à sua análise, comercialização e plantio imediato, sendo que a intensidade e persistência dessa dormência varia muito com a cultivar. Buenaventura (1956) relatou que o período de dormência, pós-colheita, de 52 variedades filipinas de arroz, variou de zero a 11 semanas. As percentagens de germinação das sementes recém-colhidas dessas variedades variaram de quase zero a 77 . Franco et al. (1997) afirmaram que as sementes de arroz caracterizam-se por apresentarem dormência pós-colheita, que pode persistir por 90 a 120 dias, dependendo da cultivar. Variações semelhantes entre cultivares de arroz também foram constatadas por Lago, Furlani e Azzini (1977) e Tella; Banzatto; Azzini, (1977).

A dormência é também influenciada pela época de colheita. Vieira (1975) verificou que a dormência das sementes da cultivar Nato foi muito intensa até 35 dias após a antese, com germinação de apenas 10\%. Após 35 dias, a dormência diminuiu e a germinação alcançou 70 a $80 \%$ aos 60 e 75 dias após a antese.

Embora o período de dormência das sementes de arroz varie entre cultivares, podendo persistir para algumas cultivares de 90 a 120 dias (FRANCO et al., 1997), as condições de armazenamento principalmente com a elevação da temperatura, segundo Bewley e Black (1994), podem reduzir esse período, proporcionando aumentos significativos na germinação das sementes.

A preservação da qualidade fisiológica das sementes mantidas em armazém convencional é um dos desafios enfrentados pela tecnologia de sementes. No armazenamento, a longevidade das sementes está sujeita à ação de fatores externos que afetam a qualidade.

Diante da escassez de informações de caráter regional sobre a influência do momento de colheita na produtividade e qualidade de sementes de arroz irrigado, com a presente pesquisa, objetivouse determinar a melhor época de colheita, em função da produtividade e qualidade de sementes de arroz BRS Jaburu produzidas e armazenadas em Boa Vista. 


\section{MATERIAL E MÉTODOS}

O experimento foi instalado em área irrigada por inundação, em solo classificado como GLEISSOLO HÁPLICO Tb Distrófico, localizada na Fazenda Santa Cecília, em Boa Vista, estado de Roraima. A cultivar de arroz (Oryza sativa L.) estudada foi a BRS Jaburu. O delineamento experimental utilizado foi o inteiramente aleatorizado, em esquema fatorial, composto de seis tratamentos (colheita aos 22; 29; 36; 44; 50 e 57 dias após o florescimento), três períodos de avaliação (zero; seis e doze meses) e quatro repetições. Cada parcela experimental constou de quatro linhas de seis metros de comprimento, espaçadas $0,30 \mathrm{~m}$ entre si, e nas colheitas foram aproveitadas as duas linhas centrais, menos $0,5 \mathrm{~m}$ nas extremidades.

As características químicas do solo do experimento foram as seguintes: P (Mehlich-1) traços; matéria orgânica 20,6 g. $\mathrm{dm}^{-3} ; \mathrm{pH}$ (água) 5,2; $\mathrm{K}^{+} 48,6 \mathrm{mg} \cdot \mathrm{dm}^{-3} ; \mathrm{Ca}^{2+}$ 0,67 cmol $\cdot \mathrm{dm}^{-3} ; \mathrm{Mg}^{2+} 0,33$ $\mathrm{cmol}_{\mathrm{c}} \mathrm{dm}^{-3}$; textura apresentando $49,6 \%$ de areia; $26,5 \%$ de argila; e $23,9 \%$ de silte.

No plantio das parcelas experimentais, foram aplicados $100 \mathrm{~kg}^{-h^{-1}} \mathrm{de}_{2} \mathrm{P}_{5}$ e $80 \mathrm{~kg} \cdot \mathrm{ha}^{-1}$ de $\mathrm{K}_{2} \mathrm{O}$ nas formas de superfosfato simples e de cloreto de potássio, respectivamente. A adubação nitrogenada, na forma de uréia, foi parcelada, sendo aplicados $60 \mathrm{~kg} \cdot \mathrm{ha}^{-1}$ de $\mathrm{N}$ no início do perfilhamento e de $60 \mathrm{~kg} \cdot \mathrm{ha}^{-1}$ na diferenciação do primórdio floral.

As práticas culturais utilizadas, para a implantação e condução dos experimentos, foram efetuadas de acordo com as recomendações técnicas para a cultura do arroz irrigado em Roraima.

Por ocasião do cacheamento, o campo foi vistoriado diariamente para a determinação da data do florescimento, ou seja, do estádio de antese quando havia aproximadamente $50 \%$ das espiguetas, considerado como o início do período de desenvolvimento e maturação dos grãos (STANSEL, 1975).

As colheitas foram iniciadas vinte e dois dias após o florescimento e então a intervalos de sete dias, até o total de 57 dias, as panículas foram colhidas manualmente no campo. A trilha foi mecanizada em trilhadeira estacionária e em seguida as sementes foram embaladas em sacos de plástico para minimizar perdas de umidade e levadas ao laboratório.

As sementes obtidas foram imediatamente avaliadas quanto à umidade (base úmida), utilizando-se duas amostras de 100 sementes cada uma, mantidas em estufa a $105^{\circ} \mathrm{C}$ por 24 horas (BRASIL, 1992). Determinou-se também a massa seca de 100 sementes na colheita (BRASIL, 1992).

As sementes foram secadas a $40^{\circ} \mathrm{C}$ por 48 a 72 horas, até atingirem umidade em torno de $13 \%$, e então colocadas em condições ambientes de armazém por 4 dias para a uniformização da umidade no interior dos grãos, quando então foram realizadas novas avaliações de conteúdo de umidade, massa de 100 sementes e produtividade. A produtividade, em kg.ha ${ }^{-1}$, foi calculada para a umidade comum de 13,0\%.

Em seguida, realizou-se o teste de germinação com quatro repetições de 100 sementes cada uma, que foram colocadas em substrato papel de germinação, formando rolos, mantidas em germinador a temperatura constante de $25^{\circ} \mathrm{C}$. A primeira contagem foi realizada aos cinco dias e a última aos quatorze dias (BRASIL, 1992). A primeira contagem de germinação foi considerada como o vigor das sementes. Os testes foram repetidos aos seis e doze meses de armazenamento.

Depois disso, as sementes remanescentes foram mantidas em condições comuns de armazém na Embrapa Roraima, em recipientes de papel, até a realização dos testes aos 6 e 12 meses, para se determinar a qualidade e a dormência das sementes no armazenamento.

Para comparação dos resultados, foram realizadas análises de variância, fazendo transformação dos valores expressos em percentagem para arcoseno $(\sqrt{\mathbf{x}+1 / 2})$, nas tabelas estão dados médios originais. Para as variáveis que apresentaram efeito significativo pelo teste $\mathrm{F}$, realizaram-se análises de regressão, utilizando-se o pacote estatístico SAS System (SAS, 2003). 


\section{RESULTADOS E DISCUSSÃO}

Os resultados obtidos das determinações de grau de umidade e massa seca de 100 sementes, logo após a colheita e depois da secagem e a produtividade de grãos de arroz, estão expressos na Tabela 1.

Pelos resultados obtidos para a determinação do conteúdo de umidade das sementes, nas seis colheitas realizadas, verifica-se redução inicial maior dos 22 aos 36 dias após o florescimento, e a seguir, moderada até os 57 dias, quando apresentou o percentual de 21,87\% (TABELA 1). Após a secagem, a umidade das sementes se estabilizou em torno de $11 \%$.

Quanto a massa seca de 100 sementes, na colheita, não houve diferença significativa entre as épocas e o valor médio foi de 2,33g nas seis colheitas realizadas (TABELA 1). Após o procedimento de secagem das sementes a massa seca de 100 sementes apresentou valor inferior na colheita dos 57 dias, com média de 2,60 g, no período. Rajanna \& Andrews (1970), estudando a maturação de sementes de arroz da cultivar Bluebonnet-50, constataram que a máxima massa seca foi obtida em época anterior, ou seja, aos 25 a 30 dias após a antese. Esse ponto em que o mais alto valor de massa seca é obtida coincide, normalmente, com o ponto de máxima qualidade fisiológica de sementes em geral.

TABELA 1 - Valores médios de produtividade de grãos (kg.ha-1, PROD), umidade na colheita $\left(\%, \mathrm{U}_{\mathrm{c}}\right)$ e após a secagem $\left(\%, U_{f}\right)$, massa de 100 grãos na colheita $\left(g, M_{c}\right)$ e após a secagem $\left(g, M_{f}\right)$, nas seis colheitas (dias) realizadas em arroz irrigado cv. BRS Jaburu cultivado em Boa Vista, RR

Table 1 - Average values of grain productivity (kg.ha-1, PROD), moisture at harvesting $\left(\%, U_{c}\right)$ and after drying (\%, $\left.U_{f}\right)$, mass of 100 grains at harvesting $\left(g, M_{c}\right)$ and after drying $\left(g, M_{f}\right)$, obtained at six harvesting dates (days) in irrigated rice BRS Jaburu, cultivated in Boa Vista, RR

\begin{tabular}{llllll}
\hline Dias & PROD & $\mathbf{U}_{\mathbf{c}}$ & $\mathbf{M}_{\mathbf{c}}$ & $\mathbf{M}_{\mathrm{f}}$ & $\mathbf{U}_{\mathrm{f}}$ \\
\hline 22 & $4.102 \mathrm{~b}$ & $27,03 \mathrm{a}$ & $2,32 \mathrm{a}$ & $2,63 \mathrm{a}$ & $10,54 \mathrm{~cd}$ \\
29 & $5.584 \mathrm{a}$ & $26,46 \mathrm{a}$ & $2,33 \mathrm{a}$ & $2,63 \mathrm{a}$ & $11,19 \mathrm{ab}$ \\
36 & $5.614 \mathrm{a}$ & $24,28 \mathrm{~b}$ & $2,33 \mathrm{a}$ & $2,63 \mathrm{a}$ & $11,64 \mathrm{a}$ \\
43 & $5.493 \mathrm{a}$ & $23,42 \mathrm{~b}$ & $2,32 \mathrm{a}$ & $2,63 \mathrm{a}$ & $11,62 \mathrm{a}$ \\
50 & $5.353 \mathrm{a}$ & $23,15 \mathrm{~b}$ & $2,32 \mathrm{a}$ & $2,63 \mathrm{a}$ & $10,98 \mathrm{bc}$ \\
57 & $5.261 \mathrm{a}$ & $21,87 \mathrm{c}$ & $2,34 \mathrm{a}$ & $2,45 \mathrm{~b}$ & $10,11 \mathrm{~d}$ \\
Média & 5.235 & 24,37 & 2,33 & 2,60 & 11,02 \\
\hline CV & $12,26 \%$ & $7,92 \%$ & $1,06 \%$ & $2,85 \%$ & $5,42 \%$ \\
$\mathrm{p}$ & $\mathrm{p}<0,01$ & $\mathrm{p}<0,01$ & n.s. & $\mathrm{p}<0,01$ & $\mathrm{p}<0,01$ \\
\hline
\end{tabular}

* Valores precedidos de mesma letra, na coluna, não diferem significativamente, segundo o teste de Tukey, a $5 \%$ de probabilidade. $\mathrm{U}_{\mathrm{c}}=$ umidade na colheita; $\mathrm{M}_{\mathrm{c}}=$ massa de 100 grãos na colheita; $\mathrm{U}_{\mathrm{f}}=$ umidade final; $\mathrm{M}_{\mathrm{f}}=$ massa final de 100 grãos.

Os valores de produtividade aumentaram acentuadamente da colheita realizada aos 22 dias para as demais colheitas pelo maior desenvolvimento e maturação dos grãos (TABELA 1). A máxima produtividade de arroz em grãos $\left(5.614 \mathrm{~kg} \cdot \mathrm{ha}^{-1}\right)$ foi obtida aos 36 dias, com teor de água relativamente alto $(24,28 \%)$. Não apresentando esta diferença, valor significativo em relação as colheitas realizadas dos 29 aos 57 dias (5.584 e $5.261 \mathrm{~kg} \cdot \mathrm{ha}^{-1}$, respectivamente). Nas colheitas realizadas aos 22 e 29 dias, o arroz apresentava teores de água maiores $(27,03$ e 26,46\%) do que nas colheitas posteriores.

É importante observar que retardar a colheita de arroz com o objetivo de colher material mais seco, reduzindo gastos com mão-de-obra e energia na secagem, pode ser antieconômico quando as perdas decorrentes da quebra de grãos e desvalorização do lote sobressaem aos ganhos oriundos do menor custo de secagem. 
Os dados de vigor, germinação e dormência de sementes de arroz BRS Jaburu observados nas colheitas e após os dois períodos de armazenamento constam na tabela 2.

Após as colheitas (zero mês), os valores percentuais de germinação foram elevados $(>91 \%)$ para todas e, em contraposição, os índices de dormência foram elevados (17\% a 53\%). As percentagens de vigor resultaram em valores pouco superiores de 40\%, sendo que na colheita aos 57 dias baixou para 28\%. Gonçalo e Maciel (1975), estudando a maturação do arroz 'EEA-404', em Pelotas (RS), verificaram, aos 22 dias após a antese, valores de vigor próximos de $90 \%$, porém, pontos máximos simultâneos para germinação, vigor e peso seco foram obtidos aos 36 dias. Neste trabalho, esses pontos máximos foram obtidos com valores inferiores. Os valores médios para sementes dormentes aumentaram significativamente da primeira colheita aos 22 dias (17\%) para a quarta colheita aos 43 dias (53\%).

Após seis meses de armazenamento, a dormência nas sementes praticamente inexistiu, com valores baixos aos seis e doze meses, concordando com os dados obtidos por Franco et al. (1997). As sementes colhidas aos 36 dias apresentaram germinação superior à das demais colheitas, mantendo a qualidade inicial (94 a 93\%) e podendo ser consideradas como as de melhor qualidade (TABELA 2).

As sementes colhidas mesmo aos 22 dias após o florescimento e nos períodos subseqüentes apresentaram boa armazenabilidade, com germinação entre 88 e $93 \%$ após 12 meses de armazenamento. A germinação das sementes foi maior quando colhidas dos 22 aos 36 dias após florescimento, sendo que aos 12 meses as colhidas aos 36 dias mantiveram o mesmo percentual inicial, enquanto as colhidas aos 22 e 29 dias perderam poder germinativo. Estes resultados no armazenamento indicam que o processo de secagem não interferiu na qualidade das sementes (FARONI et al., 1987).

TABELA 2 - Resultados médios de vigor, germinação e dormência (\%) de sementes de arroz irrigado cv. BRS Jaburu colhidas em seis épocas (dias) após florescimento e avaliadas em três épocas após a colheita, armazenadas em condições de laboratório na Embrapa Roraima, por doze meses

Table 2 - Average results of vigor, germination and dormancy (\%) of seeds of irrigated rice BRS Jaburu harvested at six different dates (days) after flowering and evaluated in three periods after harvesting, stored at laboratory conditions during 12 months

\begin{tabular}{|c|c|c|c|c|c|c|c|c|c|}
\hline \multirow{2}{*}{$\begin{array}{l}\text { Dias após } \\
\text { Florescer }\end{array}$} & \multicolumn{3}{|c|}{ Zero mês } & \multicolumn{3}{|c|}{ Seis meses } & \multicolumn{3}{|c|}{ Doze meses } \\
\hline & vigor & GERM & DORM & vigor & GERM & DORM & vigor & GERM & DORM \\
\hline 22 & 44 a A & 96 a A & $17 \mathrm{~d} A$ & $51 \mathrm{a} \mathrm{B}$ & 95 a A & $0 \mathrm{~b} \mathrm{~B}$ & $77 \mathrm{aA}$ & $91 \mathrm{ab} C$ & $1 \mathrm{a} B$ \\
\hline 29 & $41 \mathrm{a} B$ & $94 \mathrm{~b} \mathrm{~A}$ & 27 c A & $42 \mathrm{~b} B$ & $94 \mathrm{ab} A B$ & $0 \mathrm{~b} \mathrm{~B}$ & 49 с A & $91 \mathrm{ab} B$ & 2 a B \\
\hline 36 & $41 \mathrm{a} B$ & 94 b A & $36 \mathrm{~b} \mathrm{~A}$ & $41 \mathrm{~b} \mathrm{~B}$ & $94 \mathrm{ab} A$ & $1 \mathrm{~b} \mathrm{~B}$ & $58 \mathrm{~b} \mathrm{~A}$ & 93 a A & $1 \mathrm{a} B$ \\
\hline 43 & 40 a B & $95 \mathrm{ab} A$ & 53 a $\mathrm{A}$ & $41 \mathrm{~b} \mathrm{~B}$ & $92 \mathrm{~b} \mathrm{AB}$ & $2 \mathrm{~b} \mathrm{~B}$ & $47 \mathrm{c} \mathrm{A}$ & $90 \mathrm{~b} \mathrm{~B}$ & $1 \mathrm{a} B$ \\
\hline 50 & 41 a B & $94 \mathrm{ab} A$ & 47 a A & $42 \mathrm{~b} \mathrm{~A}$ & $92 \mathrm{~b} A B$ & $1 \mathrm{~b} \mathrm{~B}$ & $46 \mathrm{c} \mathrm{A}$ & $90 \mathrm{~b} \mathrm{~B}$ & $1 \mathrm{a} B$ \\
\hline 57 & $28 \mathrm{~b} \mathrm{~B}$ & $91 \mathrm{c} \mathrm{AB}$ & 51 a $\mathrm{A}$ & 32 с A & $92 \mathrm{~b} \mathrm{~A}$ & 3 a B & $32 \mathrm{~d} \mathrm{~A}$ & 88 b B & 1 a B \\
\hline $\mathrm{F}$ & $65,91 * *$ & $8,88^{* *}$ & $115,4^{* *}$ & & & & & & \\
\hline $\mathrm{CV}(\%)$ & 4,98 & 1,33 & 21,37 & & & & & & \\
\hline
\end{tabular}

Florescer = colheitas;

GERM = germinação;

DORM = dormência;

$* *=$ significativo a $1 \%$

Letras minúsculas nas colunas (colheitas) e maiúsculas nas linhas (épocas) distintas diferem entre si pelo teste de Tukey a $5 \%$ de probabilidade.

O comportamento inferior das sementes colhidas a partir dos 43 dias, durante o armazenamento, revela que a germinação não pode ser considerada separadamente, como a qualidade das sementes durante a maturação, pois a viabilidade inicial não foi substanciada por outros fatores de qualidade. Ao contrário, as sementes mostraram boa armazenabilidade. As sementes colhidas aos 57 dias apresentaram menor germinação aos 12 meses de armazenamento, em relação às das demais colheitas com valor ainda bom $(88 \%)$, mostrando que retardar a colheita das sementes perde-se em armazenabilidade. 


\section{CONCLUSÕES}

As sementes colhidas aos 22 dias após o florescimento apresentam boa qualidade, mesmo tendo alto valor de umidade inicial.

A melhor faixa de colheita, na cultivar BRS Jaburu, é dos 29 a 36 dias após o florescimento, quando as sementes apresentam maior qualidade, produtividade e reduzida dormência.

\section{REFERÊNCIAS}

BEWLEY, J. D.; BLACK, M. Seeds: physiology of development and germination. $2^{\text {nd }}$ ed. New York: Plenum Press. 1994. 445 p.

BRASIL. Ministério da Agricultura e da Reforma Agrária. Regras para análise de sementes. Brasília: SNDA/DNDV/CLAV. 1992. 365 p.

BUENAVENTURA, M. R. Dormancy periods of promising rice varieties. Philippine Agriculture, Manilla, v. 39, p. 558-570, 1956.

DORFMAN, E.; ROSA, J. L. V. Ponto de colheita e temperatura de secagem na qualidade do arroz. Lavoura Arrozeira, Porto Alegre, v. 33, n. 318, p. 69-74, 1980.

FARONI, L. R. D. et. al. Determinação do rendimento do arroz (cultivar IR 841) após secagem às temperaturas de 50,60 e $70^{\circ} \mathrm{C}$, para períodos de repouso de 30, 60, 120 e 180 minutos. Revista Brasileira de Armazenamento, Viçosa, v. 11/12, n. 1/2, p. 26-31, 1986/1987.

FRANCO, D. F. et al. Métodos para superar a dormência em sementes de arroz (Oryza sativa L). Informativo ABRATES, Curitiba, v. 7, n. 1/2, p. 118, 1997.

GONÇALO, J. F. P.; MACIEL, V. S. Maturação fisiológica de sementes de arroz (Oryza sativa L.). Semente, Brasília, v. 1, n. 1, p. 21- 25, 1975.

JULIANO, B. O. Properties of the rice caryopsis. In: LUH, B.S. (Ed.). Rice: production and utilization. Westport: CT, AVI. 1980. p. 403- 438.

LAGO, A. A.; FURLANI, P. R.; AZZINI, L. E. Efeito da temperatura de $50^{\circ} \mathrm{C}$ na quebra da dormência de sementes de arroz. Bragantia, Campinas, v. 36, p. 11-13, 1977.

LAGO, A. A. et al. Época de colheita e qualidade das sementes da cultivar de arroz irrigado 'IAC4440’. Pesquisa Agropecuária Brasileira, Brasília, v. 26, n. 2, p. 263- 268, 1991.

LUH, B. S.; MICKUS, R. R. Parboiled rice. In: LUH, B.S. (Ed.). Rice: production and utilization. Westport: CTAVI. 1980. p. 501-542.

RAJANNA, B.; ANDREWS, C. H. Trends in seed maturation of rice (Oryza sativa L.). Proceedings... Association of Official Seed Analysts, Geneva, v. 60, p. 188-196, 1970.

SAS INSTITUTE. . SAS/STAT 2003: user's guide: statistics version 9.1. Cary, 2003. 1 CD-ROM.

STANSEL, J. W. The rice plant: its development and yield. In: Six decades of rice research in Texas. Belmont: Texas Agricultural Experiment Station, 1975. p. 9-21. (Research Monograph, 4).

STEFFE, J. F.; SINGH, R. P.; MILLER JR., G. E. Harvest, drying and storage of rough rice. In: LUH, B.S. (Ed.). Rice: production and utilization. Westport: CTAVI. 1980. p. 311-359. 
TElla, R.; BANZATTO, N. V.; AZZINI, L. E. Dormência em arroz. Campinas: Instituto Agronômico. 1977. 7 p. (Circular, 82).

VIEIRA, N. R. Development and release of seed dormancy in rice (Oryza sativa L.) as related to stage of maturity. 33 f. Dissertation (Máster of Science in Seed Technology) - Mississippi State University, Mississippi State, 1975.

WEBB, B. D. Rice quality and grades. In: LUH, B.S. (Ed.). Rice: production and utilization. Westport: CTAVI. 1980. p. 543-565.

Recebido: 05/05/2007

Received: 05/05/2007

Aprovado: $31 / 10 / 2007$

Approved: 10/31/2007 